\title{
Early hospital readmission in the perspective of chronically ill patients
}

\author{
Reinternação hospitalar precoce na perspectiva de doentes crônicos
}

Elen Ferraz Teston ${ }^{1}$, Josilaine Porfírio da Silva², Mara Lucia Garanhani ${ }^{3}$, Sonia Silva Marcon ${ }^{4}$

Objective: learn, from the perspective of chronically ill patients, the reasons for rehospitalization. Methods: qualitative study with 19 patients in a general hospital. Data were collected through semi-structured interviews, submitted to content analysis and grouped into two categories. Results: the first category revealed that patients attributed the occurrence of rehospitalization to the living conditions and social determinants. The second category showed that patients believed that, by following medical advice and taking the prescribed medicines they could prevent rehospitalizations, but they did not associate these actions with other actions of self-care. Conclusion: the discharge planning is an opportunity to add new self-care actions that must be based on the real needs of individual, in order to avoid further rehospitalizations.

Descriptors: Patient Discharge; Chronic Disease; Health Planning.

Objetivo: apreender, pela perspectiva de doentes crônicos, os motivos da reinternação. Métodos: estudo qualitativo, realizado com 19 pacientes de um hospital geral. Os dados foram coletados por meio de entrevista semiestruturada, submetidos à análise de conteúdo e agrupados em duas categorias. Resultados: a primeira categoria revelou que os pacientes atribuíam a ocorrência de reinternação à condição de vida e a determinantes sociais. A segunda categoria mostrou que os pacientes acreditavam que seguir orientações médicas e tomar os medicamentos prescritos podiam evitar reinternações, mas não faziam associação dessas ações com outras de autocuidado. Conclusão: o planejamento da alta hospitalar constitui oportunidade para agregar novas ações de autocuidado listadas a partir das reais demandas individuais, para evitar novas reinternações.-

Descritores: Alta do Paciente; Doença Crônica; Planejamento em Saúde.

\footnotetext{
${ }^{1}$ Secretaria Municipal de Saúde. Jandaia do Sul, PR, Brazil.

${ }^{2}$ Hospital Dr. Eulalino Ignácio de Andrade. Londrina, PR, Brazil.

${ }^{3}$ Universidade Estadual de Londrina. Londrina, PR, Brazil.

${ }^{4}$ Universidade Estadual de Maringá. Maringá, PR, Brazil.

Corresponding author: Elen Ferraz Teston

Rua Luiz Vignoli, 597. CEP: 86900-000. Jandaia do Sul, PR, Brazil. E-mail: elen-1208@hotmail.com
} 


\section{Introduction}

Contemporary society goes through several transformations in economic, political and social levels that contribute to the change in the way the subject and the community organize their way of living. These changes directly affect the access of populations to living conditions that are more favorable to health, affecting the change of illness patterns. It is in this context that non-communicable chronic diseases arise. These represent a serious public health problem in developed countries and in middle and low income countries $^{(1-2)}$.

It is estimated that over 36 million people die each year because of chronic diseases, which corresponds to $63.0 \%$ of deaths worldwide. The main causes are cardiovascular diseases, diabetes and respiratory diseases, and the incidence of these diseases has increased rapidly among low- and middle-income countries ${ }^{(2)}$.

Characterized by having a multiple etiology, several risk factors, long latency periods and prolonged course, chronic diseases cause the burden of adverse effects on quality of life of affected individuals, and are associated with disabilities, functional invalidity and premature death $^{(1-2)}$.

Difficulties in controlling these diseases result in hospital admissions. However, this period that would, theoretically, be dedicated to the improvement in health status, does not determine the end of the need for care. When there is no constant monitoring, change in lifestyle and adherence to treatment, new hospitalizations may be required.

Hospital readmissions are a frequent problem in health institutions. An international study identified hospital readmission rates ranging from $18.2 \%$ to $25.0 \%$ among patients with cardiovascular and respiratory diseases ${ }^{(3)}$. A higher number of readmissions is observed also in patients over 60 years old because of the association with chronic diseases, entailing greater complexity and cost of treatment to the hospital system ${ }^{(4)}$.
The rehospitalization may have a reflection on the clinical condition of the patient, on the support for families and even on the effectiveness of inpatient institutions. They are, in a way, an epidemiological alert, and should trigger appropriate follow-up and integrated strategies between the different professional groups involved in the care ${ }^{(5)}$.

Whereas rehospitalization brings great burden to the health system, and discomfort to patients and their families, it is important to know the characteristics of the population that goes through this situation, in order to provide better hospital care and, especially, to provide a well thought-out and efficient plan of care after discharge aiming at reducing readmissions ${ }^{(6)}$.

Considering the complexity of chronic diseases, it is believed that the problems involved and the reduction of readmissions could be explored and better understood in the light of Self-Care Theory. According to this theory, self-care refers to activities that people do in their own benefit, taking into account the maintenance of life, health and wellbeing. Self-care is related, thus, with the individual's ability to perform physical, psychological and spiritual activities necessary to live and survive ${ }^{(7)}$.

Still, according to the theory, individuals can develop or enhance the ability for self-care, as this is learned, not instinctive. Moreover, when establishing a balance between the need for care and the individual's ability to perform it, the intervention of other people may be needed, and it is in this point that the actions of nurses may be required ${ }^{(7)}$.

The importance of self-care comes from the fact that this supports a holistic nursing care, which recognizes that environmental, social and human conditions facilitate or limit the individual's ability to engage in self-care. This is also featured in a study carried out with individuals that have Affective Bipolar Disorder, in which was stressed the importance of care and self-care guidelines for both the patient and the family, in order to minimize the effects of the disease on the patient-family relationship and facilitate 
adherence to care actions ${ }^{(8)}$.

These results indicate the need to increase the knowledge about the individual experience of the patient with the illness, the physical and social environment in which the disease is manifested and how the patient deals with it, whether in situations where the disease is under control or uncontrolled, with the consequent need for (re) hospitalization.

The objective of this study was to understand, from the perspective of the chronically ill persons, the reasons for rehospitalization.

\section{Methods}

This is a qualitative study that seeks to deepen the complexity of phenomena, facts, and particular and specific processes of clearly delimited groups in length and open for intense examination ${ }^{(9)}$ in this research focused on the perceptions that patients have about the reasons for rehospitalizations.

The study setting was the medical clinic sector of a general mid-sized hospital in the city of Londrina, PR, Brazil which had 117 beds distributed among the sectors of medical clinic (38 beds), surgical clinic (27 beds), pediatrics (20 beds) and emergency room (32 beds).

Data were collected in September 2011 through semi-structured interviews performed by one of the authors of the study, in a discrete manner and in the bedroom of patients. Interviews were guided by a semi-structured questionnaire designed to collect demographic data and information on the disease, and the guiding question was: "Tell me about the reason for your rehospitalization." Some helpful questions were used when necessary in order to facilitate further development of the theme. They are: Why do you think this hospitalization was necessary? Did you adopt any care/change after your last hospitalization? Do you think it is necessary to do something different after hospital discharge to avoid a new hospitalization for the same problem?
The interviews lasted on average 30 minutes and all were recorded on a digital device, with consent of participants, and then transcribed, preferably on the same day they were made.

It is noteworthy that we sought to conduct the interview when the patient was alone in the room and in cases when the patient was with a companion, this was asked to avoid interfering in the answers and in the development of the interview.

During the month in which data collection was performed, 145 patients were admitted to the unit. In order to identify possible participants, a hospital system where the patient had to report if he/she had undergone previous hospital admission in the last 6 months was implemented during the period of the study. A total of 35 cases of rehospitalizations were identified.

For all identified cases, compliance with the established inclusion criteria was observed, that, absence of mental confusion or neurological sequelae that could compromise and/or prevent the participation in the interview. Thus, the informants corresponded to 19 out of the 35 patients who underwent rehospitalization in the last six months.

For data analysis, the interviews were transcribed in full-length and subsequently subjected to a process of content analysis ${ }^{(9)}$. During analysis, the transcripts of interviews were read several times. Next, we sought to identify the factors involved in the phenomenon of readmission. For this, the sentences of the speeches were grouped according to their similarity of content. Later, they were organized and aggregated into reporting units according to their relationship with rehospitalization and the purpose of the study, yielding two categories.

To safeguard the identity of respondents, the lines were organized and identified by the letters "M" or " $F$ ", referring to male and female, followed by an indicative number of age and, finally, the main diagnosis of rehospitalization.

The study complied with the formal 
requirements contained in the national and international regulatory standards for research involving human beings.

\section{Results}

The 19 patients had ages ranging from 20-96 years (mean of 62.6 years), 11 of them were over 60 years old and $13(68.4 \%)$ were male. As for level of education, ten $(52.6 \%)$ had incomplete primary education, five (26.3\%) were illiterate, three (15.7\%) had completed secondary education and only one (M62) had higher education.

As for pre-existing diseases, 11 patients had cardiovascular diseases, six had respiratory diseases and five had diabetes mellitus and one was alcoholic. It was noted also that ten patients (52.6\%) had a diagnosis of hypertension, whether isolated (M-51) or associated with other diseases such as diabetes mellitus (F-65, F-81 and F-79), congestive heart failure (F-79, F-80) and chronic obstructive pulmonary disease (F-91, F-60, F-63, M-59). It is noteworthy that, for 13 of them (68.4\%), the cause of rehospitalization was decompensation of the underlying disease, and the other six were hospitalized for treatment of some kind of infection.

The fact that readmissions were associated with preexisting conditions showed, in a way, their lack of control. Thus, the analysis of the interviews resulted in the construction of two categories that express the perceptions that chronic patients have about the reasons that led to rehospitalization and the factors that could have contributed to avoid it.

\section{Patient's perception of the reason for rehospitalization}

As for the reasons that led to rehospitalization, the association to the living conditions and social determinants was common among patients, as could be seen in the following lines: I am like this because the bar girl put sugar in my milkshake, then my diabetes got worse (M-65, infected diabetic foot). I had no home, not much hygiene, did not take the medication, I was alone, then immediately I returned to the hospital (M-36, decompensated congestive heart failure). The goal I have is to be retired in order to be able to take care of my health, because I work like this for over 16 years (M-56, diabetic foot). I need to earn money to buy the medicine and take care of my health (M-96, pneumonia). The doctor told me to rest, but I'm alone and I have a sick girl, so there's no way to rest, I need to do my stuff at home (F91, decompensated chronic obstructive pulmonary disease). I tried to take care of my health, but then I met some friends and ended up drinking again. I tried to go out looking for a service, away from this life of drinking, but I did not find anything and went back to drinking. ... If I could find a service that I could be quiet in my place, I would make an effort to stop drinking, but I cannot promise that I will quit smoking (M-42, alcoholic abstinence).

\section{Factors thatcontributeto preventrehospitalization in the perception of chronically ill patients}

When questioned about the factors that could prevent rehospitalization, many respondents referred to self-care measures that should be followed, highlighting the medical prescriptions: I will obey the advice of the medicine that is very important to us. I believe a lot in medicine, in the doctor, in the hospital that has taken so much care of me and given me all support for me to be free from this disease (M79, decompensated congestive heart failure). I have to take care of myself. If the doctor indicates care, whatever he prescribes we have to follow, closely (F-81, cellulitis). Whatever the doctor tells me, I'll do (M-63, hepatic cirrhosis). I will do everything that the doctor says, from the feet to the head. Because there are three people to whom I do not lie: to my lawyer, the judge and the doctor (M-60, exacerbated chronic obstructive pulmonary disease).

Other respondents cited the correct use of medicines as the main strategy to control his disease and maintain health. I have to take care of myself, to get cured from this disease, take the right medicine (M-79, decompensated congestive heart failure). When I go home this time, I will take all the remedies correctly. There are many pills that sometimes I would forget to take, then, there is no use, I got sick again (M-42, alcoholic abstinence). I think for me to take care of my health, I need to earn money to buy medicine (F-73, chronic obstructive pulmonary 
disease). I always think of work hard for be able to buy all medicines, ointments and cure these pains (F-79, cellulitis).

\section{Discussion}

The influence of some factors such as, for example, the life context and social determinants, were evident in the speech of participants, in their perception of the causes of rehospitalization. However, these can not be experienced as impediments to changing lifestyles and realization of new actions of self-care. In this sense, nurses play an important role toward people with chronic diseases, because their actions can contribute to the maintenance of health of these patients, by encouraging self-care, considering the different perceptions individuals have on the disease and the context in which they are inserted.-

This is because the conditions in which people are born, live, grow, work and age predispose them to high risks of diseases. These circumstances, known as social determinants, shape the health of individuals as they are related to housing, and to behavioral and biological factors beyond the health system itself $f^{(10)}$.

The importance of accepting the disease and its diseased condition is also noteworthy, because, based on information and objective understanding of the disease and the process of getting ill, and their role as active subjects in this process, the individual may recognize the importance of adopting actions that promote self-care ${ }^{(11)}$. Therefore, a supportive and an effective link between patients and their families is important, so that the basic premises may be accepted for the perception of the changes required ${ }^{(12)}$.

In this context, at the moment of planning care strategies, nursing has the opportunity to enhance the individuals' responsibility for their own health, and to recognize that prevention and health education during hospitalization and in the discharge planning are important aspects in nursing interventions.

The hospital discharge planning is necessary from the very moment of admission, as it represents an opportunity for health professionals to identify the potentials of individuals and families, according to the care demands that they will later have at home, taking advantage of the teaching and learning opportunities experienced during hospitalization. In this planning process, the patient and the family must be seen as unique as beings, with strengths and weaknesses that need to be evaluated by health professionals with commitment, and technical and scientific knowledge ${ }^{(7,13)}$. In addition, they need to be enlightened and informed about the care needed to avoid rehospitalization.

This may imply the opportunity for patients and families to assign meaning to the information received and become aware, becoming able to change not only their health situation, but also to improve the whole family environment, promoting quality of food, leisure and practice of physical exercises, as these are factors that contribute to the maintenance of health ${ }^{(11)}$.

In the traditional model of health care, focused on the disease, the relationship between doctor and the patient is asymmetric because the first is considered the holder of the technical knowledge required to solve the health problems of the second. The patient is the one who is in a situation that threatens his physical integrity, due to an illness that makes him to search for the doctor, trying to find the solution to his problem ${ }^{(14)}$.

When they speak on the care to be developed to prevent rehospitalization, it was observed that many respondents attributed the solution of their health problems mainly to the doctor, as this is the one who tells patients waht they should, or should not do. Patients refute the possibility that doctors may not know the full range of factors that are intertwined with their being sick ${ }^{(10)}$.

However, at the same they time point out the importance to follow the "doctor's commands" and, in a way, are willing to follow them, they are not able to transfer these actions that characterize this "follow-up" to their personal universe. None of them mentioned or took on the responsibility to take actions that undoubtedly they heard to be necessary, for example, 
"quit drinking", "start walking" or "stop eating this or that." The data show that despite the rehospitalization episode, they are still in the contemplation phase, and not in a preparation for start a self-care action in fact.

In this sense, it is worth noting that many of the respondents were readmitted for the same reasons that caused the other hospitalization in the last 6 months. This higlights the importance of the guidelines to be appropriate to the actual condition and individual life of each patient, so that he or she may realize what is good or bad for their health. This traditional view is linked to the belief in science which tends to lead both, the patient and the doctor to take an omnipotent stance of the latter over the disease and over the patient himself. Thus, the patient is seen as having the obligation to necessarily undergo the medical supervision and, while occupying this position, the patient should have to relinquish temporarily his autonomy, power of reflection and decision, and his intuitive knowledge and, above all, experiential of the self ${ }^{(15-16)}$.

From this perspective, health professionals should promote the autonomy of users, from actions for the promotion of subjects, making them able to understand their health needs, understanding grievances and participating as co-responsible in the process of promoting health ${ }^{(11)}$. For this, it is necessary that the planning of care includes the limitations of self-care, such as social and economic status, family relationships and individual motivation to carry out the actions of self-care ${ }^{(7)}$.

However, it is important to note that, the collaboration of nursing professionals in their treatment and guidelines provided by these professionals were not mentioned in the speech of respondents. This fact triggers the need for attention to how these professionals work and identify themselves during admissions in the hospital environment. The invisibility of this professional, who is present in this environment 24 hours a day, is worrying and at the same time, indicative of the need for a closer relationship during their work toward patients and their needs. Furthermore, we should not rule out the profile of the studied population, which due to its simplicity may give the title of "doctor" to all professionals who serve them.

Considering the testimonials, we identify the essential need to invest in the hospital discharge planning focused on actions of self-care, which is a complex aspect of care and an interdisciplinary responsibility. Although not mentioned in the interviews, the nurse plays a key role in identifying the needs of the patient, in the education of families and therefore in coordinating the discharge planning, in order to educate them and motivate them for the actions of self-care and reduction of risk behaviors. These actions, when taken and implemented, constitute a protective factor against complications of chronic diseases $^{(17)}$.

When planning the discharge, thus, it is necessary to assess the patient's skills for self-care, as well as the interest and conditions that the family has to help the patient. The discharge plan has the purpose to make the patient independent and responsible for his own care at home and, where necessary, the proper preparation of the family to assume such care ${ }^{(17)}$.

In a review carried out to build a protocol for hospital discharge planning of diabetic clients of a public hospital, it appears that, although the literature has many discussions about discharge planning of patients, reports on encouraging the readiness and self-confidence of patients are still scarce. However, according to the proposed protocol presented in this study, the discharge must be the result of a plan that deliberately prepare the patient to return home, considering biological, psychological and social aspects in an integrated manner, and whenever possible, this plan must performed by a multidisciplinary team ${ }^{(17)}$.

Also in relation to the actions to prevent readmissions, the respondents were convinced of the need for proper use of medications. Their testimonies clearly show the symbolic function of the drug in their perspective, what causes them to confuse their use with the solution of their health problems. In 
addition, they design a series of expectations and representations of the medication.

This view comes from the process of transforming drugs in the central instrument of practices for their exercise, by the market logic and the concepts of health and disease. Moreover, this contributes to the transformation of health into merchandise, and the drugs and associated technologies become ends in themselves, gaining increasing autonomy, what reduces the importance of individuals in the healing process ${ }^{(18)}$.

The attention provided by the health team in a clinical practice focused only on biomedical rationality has not shown effectiveness, particularly with regard to care for people with chronic diseases ${ }^{(19-20)}$. In this sense, traditional interventions in the clinic, as the diagnosis made based on a history restricted to the collection of signs and symptoms of the disease, and from a perspective of therapy limited to prescription of drugs, have hampered the understanding of the problems and meanings involved in the disease process, and adherence of patients to the therapeutic programs offered ${ }^{(19)}$.

Finally, we reiterate the importance of aggregate new actions of self-care to the actions proposed by the respondents (following the medical guidelines and adherence to drug treatment), so that they can, in fact, contribute to preventing readmissions. These new actions must be guided primarily by the reduction of risk behaviors, as for example, adherence to healthy eating, physical exercise, and cessation of smoking and consumption of alcoholic beverages.

This study presents as limitation the fact that its results cannot be generalized, as typical of qualitative studies. However, the results are important because they allow understand the reasons of readmissions from the perspective of the chronically ill patients. This understanding may facilitate its application in practice and, particularly, in hospital discharge planning and implementation of a service that focuses on empowering the individual to self-care.

\section{Conclusion}

According to the study participants, readmissions occur as result of the living conditions and social determinants, and the factors that can contribute to prevent them are the following of medical guidelines and the use of prescribed medications.

Given these findings, the importance of the study to the care practice stands out, especially of the nursing staff, in view of the hospital discharge planning and implementation of assistance with focus on self-care. Therefore, it is necessary to take into account the real therapeutic needs, abilities and deficits of each individual. It is believed that this may qualify the assistance and thus reduce the chances of rehospitalization.

\section{Collaborations}

Teston EF and Silva JP contributed to the study design, collection, analysis and interpretation of data, article writing and final approval of the version to be published. Garanhani ML and Marcon SS contributed to the study design, analysis and interpretation of data, relevant critical review of the intellectual content and final approval of the version to be published.

\section{References}

1. Bernardes LE, Vieira EES, Lima LHO, Carvalho GCN, Silva ARV. Risk factors for chronic noncommunicable diseases in university students. Ciênc Cuid Saúde. 2015; 14(2):1115-21.

2. World Health Organization. WHO Global action plan for the prevention and control of no communicable disease 2013-2020 [Internet]. 2013 [cited 2014 Feb 20]. Available from: http:// www.who.int/nmh/events/ncd_action_plan/en/

3. Dharmarajan K, Hsieh AF, Lin Z, Bueno H, Ross JS, Horwitz LI, etal. Hospital readmission performance and patterns of readmission: retrospective cohort study of medicare admissions. BMJ. [Internet]. 2013 [cited 2015 Oct 13];347:6571. Available from:http://www.bmj.com/content/347/bmj. f6571. 
4. Merli APD, Lopes ES, Macharelli CA. Reinternações no Hospital Estadual Bauru: ocorrência e possíveis causas. Saúde Coletiva Digit [Internet]. 2013 [citado 2015 set 13]; 10(59):26-30. Disponível em http://www.redalyc.org/pdf/842/84228211005. pdf

5. Barekatain M, Maracy MR, Hassannejad R, Hosseini R. Factors associated with readmission of patients at a university hospital psychiatric Ward in Iran. Psychiatry J [Internet]. 2013 [cited 2015 Sept 10]. Available from: http://www.hindawi. com/journals/psychiatry/2013/685625

6. Souza ICP, Silva AG, Quirino ACS, Neves MS, Moreira LR. Perfil de pacientes dependentes hospitalizados e cuidadores familiares: conhecimento e preparo para as práticas do cuidado domiciliar. Rev Min Enferm. 2014; 18(1):164-72.

7. Orem DE. Nursing: concepts of practice. St. Louis: Mosby; 2005.

8. Sales DS, Oliveira EN, Brito MCC, Rodrigues TB, Souza AMA. Nursing care according to the orem's theory: care for a patient with bipolar affective disorder. Rev Pesq Fundam Care Online [Internet]. 2013 [cited 2015 Sept 10]; 5(3):311-17. Available from:http://www.seer.unirio.br/index.php/ cuidad ofundamental/article/view/2120/ pdf_875

9. Minayo MCS. O desafio do conhecimento: pesquisa qualitativa em saúde. São Paulo: Hucitec; 2013.

10. Melo MD, Egry EY. Social determinants of hospitalizations for ambulatory care sensitive conditions in Guarulhos, São Paulo. Rev Esc Enferm USP. 2014; 48(spe):129-36.

11. Silva FVF, Silva LF, Guedes MVC, Moreira TMM, Rabelo ACS, Ponte KMA. Cuidado de enfermagem fundamentado em Parse. Esc Anna Nery. 2013; 17(1):111-9.
12. Oliveira RCC, Sá LD, Silva AO, Vianna RPT, Lima AS, Oliveira AAV. Social representations about the health and diseases built by potiguara indians. Rev Enferm UFPE on line [Internet]. 2014[cited 2015 Oct 10]; 8(8):2736-45. Available from: http:// www.revista.ufpe.br/revistaenfermagem/index. php/revista/article/viewArticle/5589

13. Costa SRDD, Castro EABD. Self-care in family caregiver of dependent adults or elderly persons after hospital discharge. Rev Bras Enferm. 2014; 67(6):979-86.

14. Fertonani HP, Pires DEP, Biff D, Scherer MDA. The health care model: concepts and challenges for primary health care in Brazil. Ciênc Saúde Coletiva. 2015; 20(6):1869-78.

15. Andrade FR, Narvai PC. Population surveys as management tools and health care models. Rev Saúde Pública. 2013; 47(suppl. 3):154-60.

16. Borges SAC, Porto PN. Por que os pacientes não aderem ao tratamento? Dispositivos metodológicos para educação em saúde. Saúde Debate. 2014; 38(101):338-46.

17. Cruz IML, Mantovani MF. Orientação de enfermagem para a alta hospitalar do paciente neoplásico. Cogitare Enferm. 2014; 19(4):687-93.

18. Santos WJ, Giacomin KC, Firmo JOA. Avaliação da tecnologia das relações de cuidado nos serviços em saúde: percepção dos idosos inseridos na estratégia saúde da família em Bambuí, Brasil. Ciênc Saúde Coletiva. 2014; 19(8):3441-50.

19. Tier CG, Santos SSC, Poll MA, Hilgert RM. Health conditions for elderly in primary health care. Rev Rene. 2014; 15(4):668-75.

20. Silva LMS, Fernandes MC, Mendes EP, Evangelista $\mathrm{NC}$, Torres RAM. Interdisciplinary work in the family health strategy: focus on care and management. Rev Enferm UERJ. 2012; 20(6):7848. 